\title{
Framework for E-Learning Assessment in Dental Education: A Global Model for the Future
}

\author{
Carolina R. Arevalo, B.Eng., Ph.D.; Stephen C. Bayne, Ph.D., M.S., Ph.D.; Josie A. Beeley, \\ M.Sc., Ph.D., M.I.Biol., C.Biol.; Christine J. Brayshaw, B.D.S.; Margaret J. Cox, O.B.E., \\ B.Sc., Ph.D., F.Inst.P., C.Phys., F.K.C.; Nora H. Donaldson, B.Sc., M.Sc., Ph.D., C.Stat.; \\ Bruce S. Elson, M.Sc.; Sharon K. Grayden, B.A., M.A.; Stylianos Hatzipanagos, B.Sc., \\ M.Sc. (I.T.), M.Sc. (Ed), Ph.D., F.H.E.A.; Lynn A. Johnson, Ph.D.; Patricia A. Reynolds, \\ B.D.S., M.B.B.S., M.A.O.D.E. (Open), Ph.D., F.D.S. R.C.S.Eng, F.D.S. R.C.S.Ed., F.H.E.A.; \\ Dieter J. Schönwetter, B.Th., B.A. (Hon), M.A., Ph.D.
}

Abstract: The framework presented in this article demonstrates strategies for a global approach to e-curricula in dental education by considering a collection of outcome assessment tools. By combining the outcomes for overall assessment, a global model for a pilot project that applies e-assessment tools to virtual learning environments (VLE), including haptics, is presented. Assessment strategies from two projects, HapTEL (Haptics in Technology Enhanced Learning) and UDENTE (Universal Dental E-learning), act as case-user studies that have helped develop the proposed global framework. They incorporate additional assessment tools and include evaluations from questionnaires and stakeholders' focus groups. These measure each of the factors affecting the classical teaching/learning theory framework as defined by Entwistle in a standardized manner. A mathematical combinatorial approach is proposed to join these results together as a global assessment. With the use of haptic-based simulation learning, exercises for tooth preparation assessing enamel and dentine were compared to plastic teeth in manikins. Equivalence for student performance for haptic versus traditional preparation methods was established, thus establishing the validity of the haptic solution for performing these exercises. Further data collected from HapTEL are still being analyzed, and pilots are being conducted to validate the proposed test measures. Initial results have been encouraging, but clearly the need persists to develop additional eassessment methods for new learning domains.

Dr. Arevalo is Research Consultant, King's College London, London, UK; Dr. Bayne is Professor and Chair, Department of Cariology, Restorative Sciences, and Endodontics, School of Dentistry, University of Michigan; Dr. Beeley is Honorary Senior Research Fellow, School of Medicine, University of Glasgow, Glasgow, UK; Dr. Brayshaw is Clinical Academic Consultant, King's College London Dental Institute, London, UK; Dr. Cox is Emeritus Professor of Information Technology in Education, Haptel Laboratory, King's College London, London, UK; Dr. Donaldson is Professor of Biostatistics, King's College London Dental Institute, London, UK; Mr. Elson is Senior Research Fellow, King’s College London, London, UK; Ms. Grayden is Director of Communications, School of Dentistry, Office of the Dean, School of Dentistry, University of Michigan; Dr. Hatzipanagos is Senior Lecturer in Technology Enhanced Learning, Centre for Technology Enhanced Learning, King's College London, London, UK; Dr. Johnson is Professor and Assistant Dean for Informatics and Innovation, School of Dentistry, University of Michigan; Dr. Reynolds is Professor of Innovation in Education, Centre for Technology Enhanced Learning, King's College London, London, UK; and Dr. Schönwetter is Director of Educational Resources and Faculty Development, Faculty of Dentistry, University of Manitoba, Winnipeg, Canada. Direct correspondence and requests for reprints to Dr. Patricia A. Reynolds, Centre for Technology Enhanced Learning, King's College London, Franklin-Wilkins Building, 150 Stanford Street, London SE1 9NH, United Kingdom; p.a.reynolds@kcl.ac.uk.

Keywords: dental education, assessment, e-learning, haptics, measuring learning, educational methodology

Submitted for publication 6/3/11; accepted 1/16/12

$\mathrm{T}$ he evolution of contemporary dental education has increased the demand for online learning materials in institutional virtual learning environments (VLEs) and resource-based learning resources in areas of innovation, such as advanced laboratory simulations and haptics. ${ }^{1}$ New learning tools have raised the need for redesigned syllabi, delivery, and assessment.

Evaluating educational outcomes in traditional dentistry courses has utilized well-established qualitative and quantitative methods. However, the development of research methods for investigating the 
benefits and influence of media in learning has been controversial. ${ }^{2}$ From the earliest days of the twentieth century when the use of pictures in instruction was considered time-saving ${ }^{3}$ to the advent of metaanalysis, there have been claims and counter claims that there are no learning benefits from employing any specific medium to deliver instruction., ${ }^{2,4,5}$ Clark argued that the medium was only a delivery system and so had no effect on the learning. ${ }^{2,6}$ Compounding effects such as novelty, costs, and different instructional methods were considered to invalidate much of the traditional design of comparing one medium, e.g., television, to traditional teaching. ${ }^{5}$ The term "no significant difference" began to take on new meaning when it was used by Mielke in 1968 as a result of ambiguous data from comparison studies, regardless of the media employed. ${ }^{4}$ The infamous Clark vs. Kosma debate ${ }^{6}$ was waged before the affordances of newer technologies were known or the sociocognitive influences on learning became well accepted. Friedman in 1994 argued that new methods such as feedback and computer-mediated communication would add additional dimensions to the media that the older style media lacked. ${ }^{7} \mathrm{He}$ also described the importance of assessing outcomes, rather than comparing media, and considered the influence of the student and integration of multiple media. Carter went further in 1996 to state the influence of context and the environment on assessment methods in an era in which mass communications were evolving rapidly. ${ }^{8}$

Hence, new assessment tools (e-assessments) are now needed in response to new e-teaching/elearning systems and tools. Harasim previously explored this need, stating that as generic network tools have not been designed to support educational activities, early attempts to use them failed - thus, highlighting the need for models for virtual learning environments. ${ }^{9}$ Furthermore, it is important to improve students' learning without increasing the workload of staff, and correct learning and assessment tools in online learning become important to achieve this goal. ${ }^{10}$ These new methods should permit appropriate comparisons between e-learning and traditional teaching methods in terms of achieved learning efficacy and educational benefits, ${ }^{11}$ and they must deal with complex online interactions such as simulation and 3D environments, which present a challenge and are the main reason for rethinking outcome assessments. ${ }^{1,12}$

Several educational transitions that are occurring simultaneously — for example, a rapid expansion in dental informatics tools - drive the need for new approaches to standardized outcome assessment. A rapid decrease in dental specialty instructors and basic medical science teachers has increased the need for a more efficient and effective model of delivering educational materials to students. ${ }^{13}$ The goals for new outcome assessment tools (OATs) are threefold: there needs to be validation of the tools, standardization of approaches to e-assessment, and demonstration of equivalence with guidance for tool development. ${ }^{14}$ The objectives of this article are 1) to propose a model for outcome assessment for the range of new technologies and strategies that support teaching and learning that draws from two case-user studies and 2) to propose a potential method to synthesize these assessments into a global assessment strategy for curricula. This will form a framework for a broad series of experiments in the future.

\section{New Assessment Tools: A Theoretical Approach}

Authoring tools have already facilitated the easy creation of online contents with continuous updates. Curricula have been refined according to needs of students and teaching staff ${ }^{15}$ and have been customized to be used in local environments. An example of integrated tools and e-content is the UDENTE system (www.udente.org). Objective quantification methods of student performance from a variety of assessments in online environments need to be standardized across populations. This could enable course designers and international academic boards to evaluate and compare results of the outcomes of each hub and optimize the efficacy of various online teaching methods.

The benefits and importance of assessment have been outlined in the Higher Education Funding Council for England (HEFCE) report on enhancing learning and teaching through the use of technology. ${ }^{16}$ The report indicated that the use of technology leads to improvements in learning, teaching, and assessment, which translate into improved satisfaction, retention, and achievement. The report further supported technology-enhanced learning by indicating that "enhancing quality of teaching, learning, and meeting student expectations are significant drivers for new technology investment."

Technology-enhanced assessment and feedback have been found to improve learner engagement by greater interaction and feedback. ${ }^{17}$ The ability to 
capture a wide range of assessments online including a new approach using peer review or serious games, for instance, assists the transformation from a summative assessment-based curriculum to a more formative approach. ${ }^{18}$ Such evidence is accessible and can inform curriculum delivery and design. ${ }^{16}$ Outcome assessment will ensure that quality programs are delivered and student expectations are met. The HEFCE report also pointed out that e-assessment for learning has immediate benefit not only for students and tutors, but that "e-assessment offers tools for awarding bodies, developers, and staff. This in turn enhances the process of reporting, storing, and transferring data associated with public and internal assessments." ${ }^{\prime 16}$

That same report suggested a development framework for institutions, indicating as strategic priorities the effective management, continuous improvement, and enhancement of learning systems, resources, environment, quality of processes, and teacher workforce development. These can only be achieved through access to the full range of learning and support tools with networks to allow for a comprehensive cycle of design, teaching, learning, outcome assessment, and redesign of programs and curricula. The development goal stated in the report was that "institutions should have effective mechanisms for evaluating learners' experiences of learning, including learning with technology." 16

This topic has been further explored by Cox et al., ${ }^{19}$ who defined types of computer-assisted assessment. These authors presented the advantages of new methods for formative and summative assessments and the application of information and communications technology to support these processes. However, they were aware of the disadvantages of computer-supported assessments, such as the time it takes for development of the tools, data protection, and stress on learners who are not familiar with the use of software. These authors also underlined the importance of human interaction, especially in resolving plagiarism issues.

Online assessment or e-assessment has been built on traditional assessment techniques and provides new and novel assessment methods for learning, although the full range of innovative assessment methods needed remains to be designed and validated. Recent innovative methods to assess students' learning in VLE have been drawn from authentic, real-life practices, ${ }^{20-22}$ behaviors, and thinking that students will be required to emulate as professionals. In addition to providing newer and more refined methods of assessment that support online learning, it is necessary to design assessments that are consistent with the oral health competencies that students are expected to achieve. ${ }^{23-25}$ Tools utilized for scientific courses can be extrapolated into oral health education as assessment tools that highlight the possibility of tools aiding instructors in providing feedback to students from multiple-choice tests, in which little input from the instructor is needed, to systems designed to alert the instructor if an interaction with a student is recorded. ${ }^{3}$

This article examines one approach to utilizing Entwistle's factors affecting quality of learning. His flow diagram (Figure 1) breaks down the components contributing to the learning process in terms of the influences of the student (orange boxes), the teacher (blue boxes), and the institution (yellow boxes). ${ }^{26,27}$ This diagram is an adapted version of the enhancing teaching and learning environments project model. It gives us a clearer view of the interrelationships and influences that may impact the quality of student learning by combining students' characteristics and relationships with their previous knowledge and learning environment. ${ }^{26}$ This model also helps us distinguish between the content of the course and the teaching and learning environment and enables measures to be identified for evaluation of each of the influencing factors. Other authors have justified the use of other models for the assessment of online learning. For example, Crippen suggested the use of the Stiggins model, which links assessment alternatives to achievement targets $;{ }^{10}$ however, this model does not take into account students' preferences in learning and previous knowledge and environments as the Entwistle model does.

Traditional dental education is being challenged by major curricular innovations such as Universal Dental E-Learning (UDENTE), ${ }^{11}$ previously International Virtual Dental School (IVIDENT), and Haptics in Technology Enhanced Learning (HapTEL; www.haptel.kcl.ac.uk). IVIDENT, developed as a flexible curriculum platform to meet the educational needs of net generation students, was launched by King's College London Dental Institute, one of the largest dental schools in Europe. Supported by United Kingdom government funding, UDENTE provides innovative approaches to the delivery of all aspects of dental education. An earlier example of a virtual learning environment is the Virtual- $U$, a system designed to encourage adoption of collaborative learning approaches and the development of tools to meet needs of instructors and students. ${ }^{2}$ 


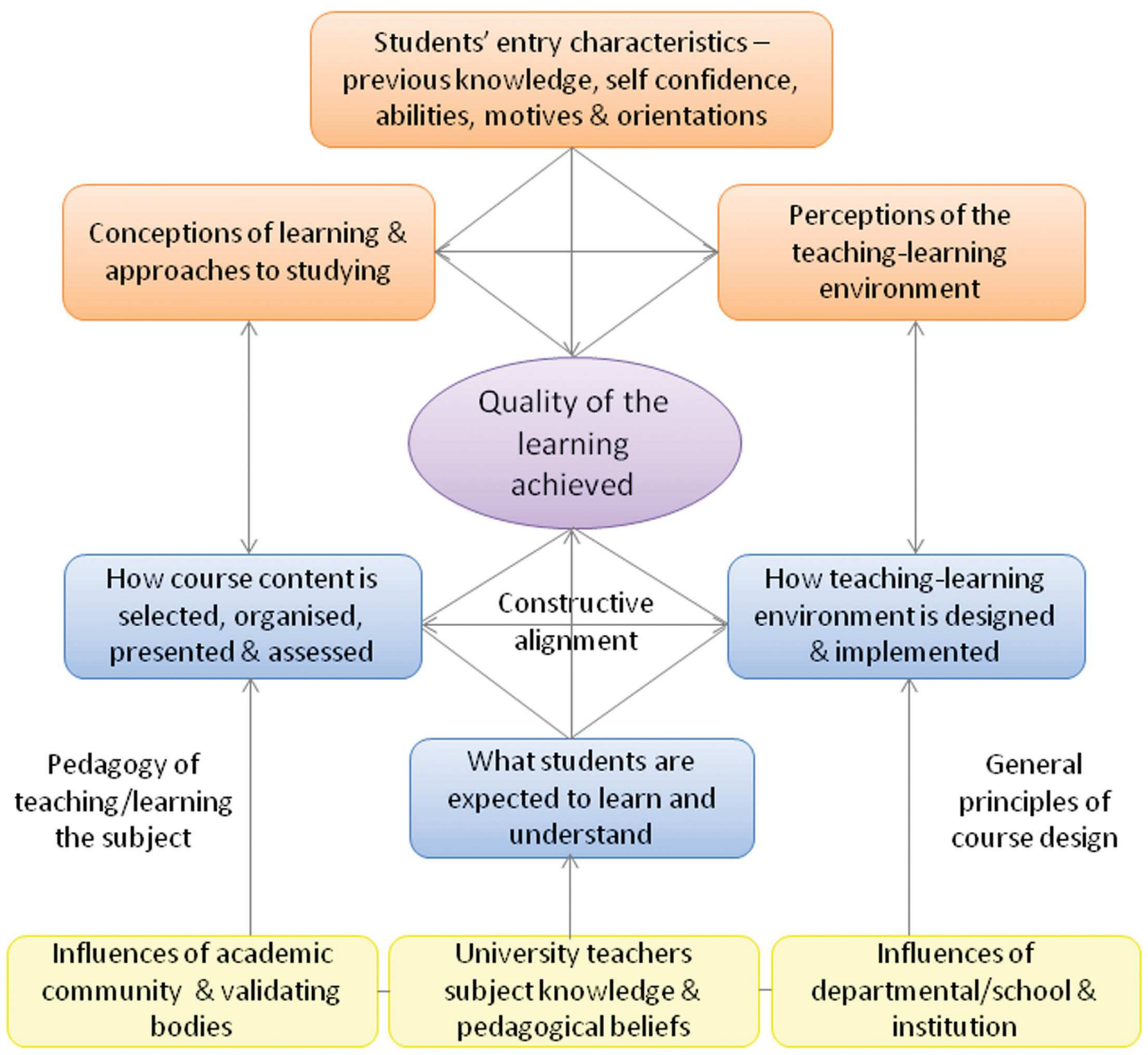

KEY

\begin{tabular}{|l|}
\hline Orange $=$ Student factors \\
Blue $=$ Teacher factors \\
\hline Yellow $=$ Institutional factors \\
\hline Purple = Quality of learning \\
\hline
\end{tabular}

Figure 1. Factors affecting learning experience

Source: Figure adapted from Entwistle N. Teaching and learning in diverse university settings: analytic frameworks for integrating different data sources. Paper presented at Fifth Annual Conference on Teaching and Learning Research Program, November 22-24, 2004, Cardiff, Wales. 
This system provides new research and assessment tools to provide instructors with a monitoring system for participation, contribution, and performance of students in their courses, as well as the students' interaction with the system - thus presenting real-time information, which is an advantage when compared with traditional monitoring methods. ${ }^{2}$ HapTEL focuses on design, development, and evaluation of a virtual learning system that will be able to incorporate haptics, the study of human touch and interaction with the external environment via touch and synthetic devices. Preclinical dental students have traditionally learned tooth preparation and restoration skills on manikins with plastic teeth. Those teeth, unlike haptics, can only be used once, are expensive, and do not record or replay the procedure. Virtual learning systems must be reliable and cost-effective, must ensure quality of learning, and, as in a physical set-up, must continue to ensure patient safety. The HapTEL project is part of the Technology-Enhanced Learning Programme (www.tlrp.org/tel) jointly funded by the UK Economic and Social Research Council and the UK Engineering and Physical Sciences Research Council. Assessing educational outcomes within such innovative online learning environments, as presented at the International Meeting on Methodological Issues in Oral Health Research, concluded that "new methods of outcome assessments need to be developed to evaluate future teaching strategies and student attainment."14

\section{Methods}

\section{Objective 1}

The global assessment model chosen for developing the foundation for a qualitative analysis was based on the Entwistle learning theory ${ }^{26,27}$ (Figure 1). It is an analytic framework for students' learning experiences. The Entwistle theory from 2004 consists of the following factors: 1) student entry characteristics, 2) student conceptions of learning, 3) student attitudes and perceptions; 4) quality of learning as rated by instructors; 5) course construction to achieve learning; 6) instructor excellence of knowledge and presentation; and 7) environmental influences of institution.

In the UDENTE project, evaluation of the learning environment was carried out in seven pilot projects across the globe. Austria, Germany, Italy, Malaysia, Malta, Norway, and the United Kingdom participated in this evaluation. Technical access to the system, functional components, and assessment were tested with pre- and post-course learning questionnaires, staff interviews, and collection of data from interaction with the environment. ${ }^{28}$

The HapTEL project is an example of new assessment strategies that are part of an evaluation framework for the future. ${ }^{29}$ The components of the HapTEL evaluation strategy (summarized in Figure 2) point to the extensive number of considerations in any comprehensive assessment strategy. This includes a three-strand approach evaluating the technical, curricular, and educational aspects of the project, with the range of measures employed. Table 1 shows the methodology used for the combinational assessment measures in the HapTEL project. Table 2 describes four types of assessment (cognitive, affective, psychomotor, and combination) and the comparison of traditional assessment and e-assessment. ${ }^{30}$ The e-assessment techniques have not only built on traditional assessment techniques but also provide new methods of assessing student learning. Collection of quantitative data for the HapTEL project included an Information and Communication Technology (ICT) questionnaire and the ARCO Spatial Relations test. These were applied to measure students' attitudes, learner-computer interaction, cognition, and learning and psychomotor skills. Comparisons were also made between cavity preparation in a plastic tooth and virtual tooth in two groups: manikin and HapTEL.

\section{Objective 2}

The provision of an overall e-curriculum assessment combines and integrates the Entwistle factors in a proposed mathematical model. There are several layers to this process. The first is to test the individual components in pilot studies at appropriate sampling levels. A minimum sample size (e.g., power analysis) to achieve a desired level of statistical power with a given model prior to data collection and the sample size calculation will be affected by the normality of the data obtained. The generally accepted rule is that a Structural Equation Model (SEM) requires ten participants for every free parameter estimated and that, for non-normally distributed data, this number should be increased to about fifteen. ${ }^{31,32}$ To measure eight parameters, therefore, a sample size of eighty to 120 should be required. With 180 students in each undergraduate year, the numbers are adequate. Nevertheless, a power calculation will be provided with the analysis, based on the approach described by MacCallum et al., ${ }^{33}$ using the root mean 


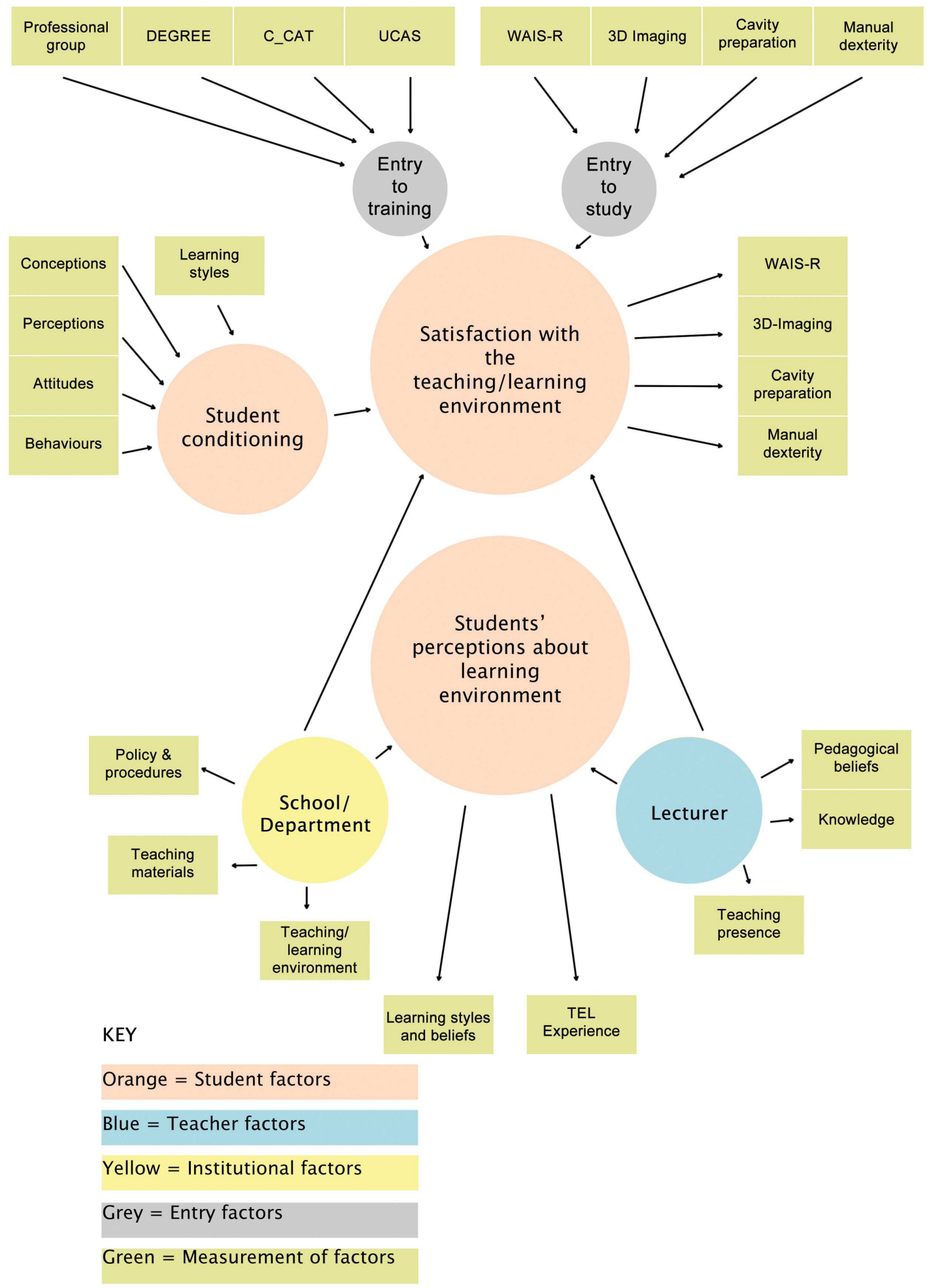

Figure 2. A framework of student conditioning to students' perceptions about their learning environment Note: Some measures are duplicated in the framework because they may yield further relevant data. 
Table 1. Examples of use of combinational assessment measures in the HapTEL project

\begin{tabular}{|c|c|c|}
\hline Activities/Groups & $\begin{array}{l}\text { Traditional Phantom Head Session: } \\
\text { Plastic Teeth Control Group }\end{array}$ & $\begin{array}{l}\text { HapTEL Session: } \\
\text { Virtual Teeth Experimental Group }\end{array}$ \\
\hline Pre- and post-test data & \multicolumn{2}{|c|}{$\begin{array}{l}\text { Attitude towards ICT and new technologies survey: spatial reasoning, 3-D perceptions, } \\
\text { and psychometric skills (fine motor, gross motor, and hand-eye coordination) }\end{array}$} \\
\hline Student worksheet focused on & $\begin{array}{l}\text { Cavity preparation } \\
\text { Post questionnaire (retrospective) } \\
\text { Characteristics of the plastic models }\end{array}$ & $\begin{array}{l}\text { Cavity preparation } \\
\text { Introspective and retrospective (paired } \\
\text { observations) } \\
\text { Characteristics of the VR models } \\
\text { Features of the system } \\
\text { Configuration of the hardware }\end{array}$ \\
\hline Videos & \multicolumn{2}{|l|}{ Videos of selected pairs of students } \\
\hline Practical task & $\begin{array}{l}\text { Plastic teeth preparation: tasks } 1,2,3 \\
\text { Post task assessment cavity preparation } \\
\text { using plastic teeth }\end{array}$ & $\begin{array}{l}\text { Virtual haptic teeth preparation: tasks } \\
1,2,3 \\
\text { Post task assessment cavity preparation } \\
\text { using plastic teeth }\end{array}$ \\
\hline \multirow[t]{2}{*}{ Evaluation } & \multicolumn{2}{|c|}{$\begin{array}{l}\text { Post cavity preparation questionnaire comparing opinions on task completions between } \\
\text { haptics and phantom } \\
\text { Tutors' assessment on post cavity preparations } \\
\text { Students' self-assessment on post cavity preparations }\end{array}$} \\
\hline & \multicolumn{2}{|l|}{ Researchers' and tutors' observations } \\
\hline
\end{tabular}

square error of approximation. In addition a general linear model is proposed that considers potential interaction effects for the Entwistle factors.

Two principal desired outcomes have driven the evaluation framework quality of learning and students' satisfaction with the teaching-learning environment. A structural equation modelling approach is proposed for the two learning environments (online and traditional) that will help to develop a theoretical model for a global strategy. The method allows an evaluation of the interaction of lecturer-student and student-student attributes with the type of learning environment.

A third consideration is the relative weighting of the factors. A series of student and faculty focus groups will be considered to determine what factors deserve more weight. This same process also needs to take into account the potential limitations of certain educational processes and the overall impact on the e-assessment outcome.

\section{Results}

\section{Objective 1}

A number of assessment measures can be tabulated according to Entwistle's framework (Table
2). The following series of outcome assessment approaches are proposed.

The first factor in the flowchart (Figure 1) describes the student's entry characteristics, in which previous knowledge, self-confidence abilities, motives, and orientations are assessed. These characteristics are of two types: a) entry-to-training characteristics and b) entry-to-study characteristics. The entry-to-training characteristics of students refer to A-levels, CAT (Clinical Aptitude Tests), Canadian Dental Aptitude Tests (DAT) scores, dexterity skill tests such as soap or chalk carvings (Canadian), previous degree, and memberships in any professional groups. The second factor refers to the student's conceptions of learning and approaches to study. These can be assessed by a Learning Styles Questionnaire $\left(K_{\text {olb' }}{ }^{34}\right)$ and experience of ICT, assessed with an ICT aptitudes questionnaire. Data in this stage can be collated automatically on students' profiles and pathways that track student use of a VLE. The third factor consists of the student's attitudes and perceptions of the teaching-learning environment, including beliefs about learning. ${ }^{35}$ Evidence collected using questionnaires and interviews is based on students' perceptions of the environment (by interviews with learners); opinions about their learning; attitude towards their peers; perceived behavioral control 


\section{Table 2. Comparison of traditional and online student learning assessment strategies}

\begin{tabular}{|c|c|c|}
\hline Assessment Types/Levels & Traditional Assessment Techniques & Online Assessment Techniques \\
\hline \multicolumn{3}{|l|}{ 1. Cognitive } \\
\hline Knowledge and comprehension & - Multiple-choice items & $\begin{array}{l}\text { - Multiple-choice items } \\
\text { - Crossword puzzles } \\
\text { - Word searches } \\
\text { - Other online games } \\
\text { - Identification of anatomy and functions }\end{array}$ \\
\hline Application & - Case-based multiple-choice items & $\begin{array}{l}\text { - Case-based multiple-choice items } \\
\text { - Transfer cognitive learning to simulated } \\
\text { environments }\end{array}$ \\
\hline Analysis & $\begin{array}{l}\text { - Short answer } \\
\text { - Structured essay }\end{array}$ & $\begin{array}{l}\text { - Short answer } \\
\text { - Structured essay } \\
\text { - Take anatomical items apart and place } \\
\text { back in correct placement (puzzles) }\end{array}$ \\
\hline Synthesis & $\begin{array}{l}\text { - Short answer } \\
\text { - Structured essay }\end{array}$ & $\begin{array}{l}\text { - Short answer } \\
\text { - Structured essay } \\
\text { - Applying cognitive learning to novel } \\
\text { simulation } \\
\text { - Virtual-reality: computer-based clinical } \\
\text { scenarios }\end{array}$ \\
\hline Evaluation & $\begin{array}{l}\text { - Short answer } \\
\text { - Structured essay }\end{array}$ & $\begin{array}{l}\text { - Short answer } \\
\text { - Structured essay }\end{array}$ \\
\hline 2. Affective & $\begin{array}{l}\text { - Patient-student communication survey } \\
\text { - Assessment by observation } \\
\text { - Standardized patients } \\
\text { - Short answer } \\
\text { - Structured essay }\end{array}$ & $\begin{array}{l}\text { - Virtual reality: computer-based clinical } \\
\text { scenarios } \\
\text { - Structured collaborative problem-solving } \\
\text { tasks }\end{array}$ \\
\hline 3. Psychomotor & $\begin{array}{l}\text { - Clinical competency exams } \\
\text { - OSCE } \\
\text { - Triple jump exercise (PBL) } \\
\text { - Use of simulation manikins }\end{array}$ & $\begin{array}{l}\text { - Simulation with grades } \\
\text { - Video analysis } \\
\text { - Haptics }\end{array}$ \\
\hline 4. Combination of all three & $\begin{array}{l}\text { - Record review } \\
\text { - Learning portfolios } \\
\text { - Viva voce }\end{array}$ & $\begin{array}{l}\text { - Online learning portfolios } \\
\text { - Videoconferencing }\end{array}$ \\
\hline
\end{tabular}

Source: Adapted with permission from Schönwetter DJ, Reynolds PA, Eaton KA, de Vries J. Online learning in dentistry: an overview of the future direction for dental education. J Oral Rehabil 2010;37:927-40.

(perceived ability to perform a particular behavior); subjective norm (individual's perceptions of social beliefs that a behavior will or will not be performed); and perceived intentions and expectations from the learning environment or course. The first item can be assessed by interview, and the others by a student attitude test in the form of an ICT questionnaire (semantic differential [a scaling tool] and a questionnaire based on Theory of Planned Behavior) ${ }^{35}$ before and after the students' experience with any online learning tools, e.g., the haptic devices (Table 3).

The fourth factor refers to the quality of learning achieved as rated by the tutors and demonstrators. This involves assessment of 3D perception through the object assembly task from the Wechsler Adult Intelligence Scale-Revised (WAIS-R); assessment of the accuracy of cavity preparation scored by asking stu- dents to cut a virtual cavity (the use of Voxals allows the assessment of amount of "good" tooth vs. "bad" tooth that has been cut via percentage scores); 3D imaging of preparation; and manual dexterity skills. This is a baseline and end-of-study assessment to afford a measure of value-added in the skills acquired.

The fifth factor in the flowchart is how course content is selected, organized, presented, and assessed. Whereas factors 1-3 canvassed students' expectations of learning, here it is necessary to review the Teaching Quality Assurance institutional documentation on production and evaluation of learning materials and policies and procedures in the university, school, and local departments. Evaluation of the design and implementation of the teaching-learning environment was based on the narrative analysis of in-depth interviews with teaching staff, peer assess- 


\section{Table 3. Elaboration of student attitudinal question- naires}

The questionnaires were developed from behavioral prediction models (Theory of Planned Behavior, Technology Acceptance Model, and motivational models). The items used were taken from existing scales in these models that measure the following constructs:

- Attitude

- Perceived behavioral control

- Subjective norms

- Self-efficacy

- Perceived usefulness

- Perceived ease of use

- System quality

- Task cost value

- Mastery goals

- Cognitive absorption

- Emotion

- Interest

- Satisfaction

- Intention

The aim of the questionnaires was to see which factors affect student satisfaction with simulators and their subsequent intention to use them. This was achieved by conducting structural equation modelling.

ments, student course, and instructor evaluations including Student's Evaluation of Educational Quality (SEEQ), ${ }^{36}$ video observations, and focus groups. Although the process of evaluation of this factor is purely qualitative, the final outcome can be provided in the form of an ordinal variable that numerically indicates the overall quality level of the course. The influences of academic community and validating bodies were evaluated through in-depth interviews with teaching staff and review of documentation and from information arising from other TEL projects.

Another factor affecting learning experience is the university teacher's subject knowledge and pedagogical beliefs, and this can be evaluated with in-depth interviews with teaching staff, video observations, and completion of a questionnaire to assess their pedagogical beliefs based on Bloom's and Shulman's taxonomies. ${ }^{37,38}$ The final factor outlined by Entwistle ${ }^{26,27}$ consists of the influences of department, school, and institution, which are again assessed through in-depth interviews with teaching staff and through the review of documentation as above.

Relevance to HapTEL project. The assessment of modalities used to evaluate innovative TEL tools fits into a three-stranded approach: technical, curriculum, and educational. These overlapping strands evaluate the impact of TEL devices on teach- ing and learning using Entwistle's framework. First, to capture the perceptions of the teaching-learning environment, we employed students' attitude tests to measure opinions about their learning, attitude towards their peers, perceived behavioral control, subjective norm, and behavioral intentions. The teaching and learning strategies were measured through observation and video recordings of student-tutor-ICT strategies and interactions, the development of a comprehensive taxonomy of the features of haptic devices and online feedback and how they contributed to students' learning, and the application and development of theories relating to factors that impact upon student learning in a TEL environment. These were used to evaluate students' 3D perceptions, levels of immersion in the virtual environment, development of clinical concepts and skills, human-computer interactions, impact of the situational context, and institutionalization of TEL into dental education programs. ${ }^{39,40}$

The clinicians focus group's assessment objectives were used to conduct initial requirements and analysis of skills and concepts to be taught in order to identify research methods for measuring the impact of haptics on dental students' learning and to identify theories to provide foundations for the methods. The methods used were literature review of TEL research, methods, and theories; focus group discussions amongst clinicians; questionnaire and interviews with clinicians; and developing a taxonomy of skills and concepts. The technical strand evaluation stages, from rudimentary models of oral cavity, established the interfaces for the teaching station and online screen displays to then either modify and develop teaching-related activities or develop simulations for dental cuts and tools. The curriculum and content strand evaluation stages included the identification of the course components to include haptics and developing a taxonomy of concepts and skills in existing courses. The content for online simulations is then developed and expanded, with collection and analysis of audiovisual recordings or training episodes followed by the categorization of components. There has been a change in the curriculum from Year 2 to Year 1, so that all students were being taught the same procedures at the same time, making it easier to replace current manikin practices with the haptics system.

After comparing the results in the two groups (Manikin and HapTEL) groups, we observed significant results and advantages for the HapTEL method. First, the HapTEL group students were provided 
with individual feedback without the need to wait for tutors. The HapTEL activity enabled the students to improve because they were able to practice on a multitude of occasions vs. the traditional activity in which only two plastic teeth were provided per session. Furthermore, the HapTEL method enabled students to replay their procedure to observe areas for development. The main result observed is that Year 1 students who were taught only using the HapTEL virtual system and had never treated a plastic or real tooth performed as well as the traditionally taught students when preparing a plastic tooth cavity at the end of term. ${ }^{41}$

Relevance to UDENTE. The results from the pilot study indicated that the learning experience was positive and the contents of the system easy to use and useful. The groups accepted the UDENTE system and its approach to learning. The pre-course questionnaires indicated the students' familiarity with computers, with the post-questionnaire indicating that the system had helped them consolidate learning and have a record of their interactions with the system. Even more positive was the indication that students perceived the course to be of a similar or better quality than in that of traditional face-to-face courses. ${ }^{28,42}$

\section{Objective 2}

The Entwistle model has enabled a new approach to be synthesized into a global assessment strategy for curricula. Figure 2 proposes a theoretical model of five first-order latent factors (entry-totraining, baseline entry-to-study assessment, student conditioning, college/school, and lecturer quality). Only one of the latent factors (student conditioning) assumed formative indicators, while all the rest assumed reflective indicators. The componentsbased approach - also known as partial least square (PLS) - was applied, which can model formative indicators. ${ }^{43-45}$

The entry-to-study characteristics are measures of the quality of learning evaluated at baseline and at the end of the course. Therefore, the level of value-added quality in learning was estimated and compared between two different learning environments (e-learning and traditional). They refer to 3D perception using object assembly task from Wechsler Adult Intelligence Scale-Revised, accuracy of cavity preparation evaluated by scoring cavity cut, and 3D imaging of preparation and manual dexterity skills. As Figure 2 shows, the students' perception of their learning environment is central and depends on institutional and lecturer factors. However, their own learning styles, beliefs, and experience of learning online need to be considered. The proposed mathematical model, with layering in terms of sample size and a power analysis, a linear construct of the Entwistle factors, and the relative weighting of factors need to be further developed.

\section{Discussion and Conclusion}

Assessments of HapTEL include the development of 3D conceptual understanding and manipulative skills. The contributions include a comprehensive taxonomy of the features of such devices and how they contribute to students' skills. Additionally, these allow for modification of theories relating to factors that impact upon student learning in a TEL environment. Modifying such taxonomies and theories is relevant to this article as the complexity of these new environments develops and changes, challenging the assessments employed. In HapTEL, the wide range of proposed data are still being collected and analyzed. A pilot project continues to be conducted to validate the test measures including approaches such as video analysis. One important early outcome has been improvement in students' practical skills when drilling at the interface of enamel and dentine due to the effects of learning with haptic feedback.

For the focus group evaluation, the results of the initial requirements analysis for teaching with haptics included technical skills for cavity preparation. The technical strand results of curriculum setting and procedures involved students' observation in clinical laboratory, to be able to draw a comparison between simple haptic devices and traditional clinical skills, phantom-head teaching. A comparison was made of the feedback to students by using the haptic device replay facility versus feedback given during a face-to-face tutorial. The curriculum and context strand aims to evaluate the way that TEL can enhance the quality of learning and the kinds of pedagogical practices that will emerge around innovation with TEL. This is still a work in progress. The evaluation theories and methods developed for this strand will take account of influencing factors and will investigate the way in which human-computer interface haptic devices and online simulations can contribute to the students' learning and will develop methods to measure how these new technologies can be embedded in dental education. 
The challenge continues when the new worlds of learning combine to create new learning experiences in new multisensory environments that may or may not be blended with reality. The HapTEL project can become a collaborative learning tool when used in combination with universal platform solutions like UDENTE, offering new opportunities for practical training across the world. The fact that UDENTE has already been successful in pilot projects proves that not only a future collaboration of HapTEL and UDENTE is possible but that the approach to learning based in students' preferences is appropriate. It has provided a system for flexible dissemination and assessment, improving student experience and allowing for accurate and fast feedback. It also improves the teaching and administrative experience by allowing student monitoring and activity.

A wide range of evaluation tools are required to analyze the educational outcomes from new online learning domains, as these constitute a significant departure from traditional teaching and learning approaches. ${ }^{30}$ Although initial results are encouraging, new methods of outcome assessments need to be developed to evaluate future teaching strategies and student attainment. New outcome assessment tools will require validation and further work to prove that the outcomes are at least equivalent to traditional methods. It is of great importance to ensure that these are standardized, valid, and practical.

A global approach to identifying e-assessment tools is proposed, a method of synthesizing those results for the purposes of an online curriculum is suggested, and the challenges for standardization, validation, and equivalence testing are discussed. Indeed, policymakers will need to consider a radical cultural change in educational systems to ensure that modern and relevant curricula that blend face-toface and online systems are developed and assessed appropriately. A considerable amount of work lies ahead, but these important and critical first steps set the stage for the future for new e-teaching, e-learning, and e-assessment systems.

\section{Acknowledgments}

The authors wish to acknowledge all those who took part in a 2010 International Association for Dental Research symposium and to all contributing researchers in the UDENTE and HapTEL projects, especially Ms. Tracy-Ann Green who contributed Table 3 from her doctoral research project to investigate dental students' satisfaction with dental simulators. Special thanks also goes to Professor Tim
Newton and Professor Jon Hindmarsh, who were the main designers of much of the instrumentation and methods in the HapTEL project.

\section{REFERENCES}

1. Cox M. The changing nature of researching information technology in education. In: McDougall A, Murnane J, Jones A, Reynolds N, eds. Researching IT in education: theory, practice, and future directions. New York: Routledge, 2010.

2. Clark RE. Reconsidering research on learning from media. Rev Educ Res 1983;53(4):445-59.

3. Thorndike EL. Education. New York: Macmillan, 1912.

4. Mielke KW. Questioning the questions of ETV research. Educ Broadcasting Rev 1968;2:6-15.

5. Clark RE. Confounding in educational computing research. J Educ Comput Res 1985;1(2):137-48.

6. Clark RE. Media will never influence learning, 1993. At: www.ucs.mun.ca/ bmann/0_ARTICLES/Media_Clark. html. Accessed: September 20, 2011.

7. Friedman CP. The research we should be doing. Acad Med 1994;69(6):455-7.

8. Carter V. Do media influence learning? Revisiting the debate in the context of distance education. Open Learning, February 1996:31-40.

9. Harasim L. A framework for online learning: the virtual-U. IEEE Comp 1999;32(9):44-9.

10. Crippen KJ. Rethinking course assessment: creating accountability with web-based tools. J Sci Educ Technol 2003;12(4):431-8.

11. Schönwetter DJ, Reynolds PA, Eaton KA, de Vries J. Online learning in dentistry: an overview of the future direction for dental education. J Oral Rehabil 2010;37:927-40.

12. Hatzipanagos S. Closing the loop: how tutor engagement with formative assessment practices can have an impact on the learner experience. In: Kemp P, Atfield R, eds. Enhancing learning through assessment. London: Threshold Press, 2010.

13. Fitzpatrick S. Staffing levels of dental clinical academics and dental clinical teachers in UK dental schools (as at 31 July 2008). London: DSC, 2009.

14. Reynolds PA, Johnson L, Bayne S, Schönwetter DJ, Beeley JA, Grayden S. Outcome assessment of teaching strategies (OATS) in the new world of learners: sowing wild OATS. J Dent Res 2010;89(Spec Iss):3734 (Abstract).

15. Online Learning Task Force. Collaborate to compete: seizing the opportunity of online learning for UK higher education. London: Higher Education Funding Council for England, 2011.

16. Higher Education Funding Council for England (HEFCE). Enhancing learning and teaching through the use of technology: a revised approach to HEFCE's strategy for e-learning. London: Higher Education Funding Council for England, 2009.

17. Joint Information Systems Committee (JISC). Effective assessment in a digital age: a guide to technologyenhanced assessment and feedback, 2011. At: www.jisc. ac.uk/media/documents/programmes/elearning/digiassass_eada.pdf. Accessed: September 30, 2011. 
18. Nicol D, Macfarlane-Dick D. Formative assessment and self-regulated learning: a model and seven principles of good feedback practice. Stud Higher Educ 2006;31(2):199-218.

19. Cox MJ, Schleyer T, Johnson LA, Eaton KA, Reynolds PA. Making a mark: taking assessment to technology. $\mathrm{Br}$ Dent J 2008;205:33-9.

20. Norman G. Research in clinical reasoning: past history and current trends. Med Educ 2005;39:418-27.

21. Herrington T, Herrington J. Authentic learning environments in higher education. University of Wollongong, Australia: Information Science Publishing, 2006:86.

22. Reif M. Alternative assessment for adult learners. Adult Learning 1995;6:12-4.

23. Eaton KA, Reynolds PA, Mason R, Cardell R. Assuring quality. Br Dent J 2008;205:145-50.

24. Chambers DW. Competency-based dental education in context. Eur J Dent Educ 1998;2:8-13.

25. Shanley DB. The DentEd thematic network project: educational methods. In: Shanley DB, ed. Dental education in Europe: towards convergence. Budapest: Dental Press kft, 2001:9-15.

26. Entwistle N. Teaching and learning in diverse university settings: analytic frameworks for integrating different data sources. Paper presented at $5^{\text {th }}$ Annual Conference on Teaching \& Learning Research Program, November 22-24, 2004, Cardiff, Wales.

27. Entwistle NJ, Peterson ER. Conceptions of learning and knowledge in higher education: relationships with study behavior and influences of learning environments. Int $\mathrm{J}$ Educ Res 2004;41:407-28.

28. Berr L, Reynolds PA, Stagnell S, et al. Initial user testing of UDENTE (Universal Dental eLearning) at seven international centers. Proceedings of 2010 Annual ADEE Meeting, August 25-28, 2010, Amsterdam, The Netherlands.

29. Reynolds P, Newton T, Cox MJ, Harwin WS, Elson B, Woolford M, et al. Methods to teach and evaluate dental clinical skills using haptics. J Dent Res 2010;87(Spec Iss):B (Abstract).

30. Reynolds PA, Brayshaw CJ, Hatzipanagos S, Schönwetter $\mathrm{D}$, Elson B. Assessing educational outcomes in innovative online learning. Proceedings of International Meeting on Methodological Issues in Oral Health Research, April 21-23, 2010, Istanbul, Turkey.

31. Bentler PM, Chou CP. Practical issues in structural modeling. Sociol Methods Res 1987;16(1):78-117.
32. Hair JF Jr, Black WC. Multivariate data analysis. Upper Saddle River, NJ: Pearson Prentice Hall, 2006.

33. MacCallum RC, Browne MW, Sugawara HM. Power analysis and determination of sample size for covariance structure modeling. Psychol Methods 1996;1(2):130-49.

34. Kolb DA. Experiential learning: experience as the source of learning and development. Englewood Cliffs, NJ: Prentice Hall, 1984.

35. Ajzen I. The theory of planned behavior. In: Organizational behavior and human decision. San Diego: Academic Press, 1991:179-211.

36. Marsh HW. SEEQ: a reliable, valid, and useful instrument for collecting students' evaluations of university teaching. Br J Educ Psychol 1992;52:77-95.

37. Bloom BS, Engelhart MD, Furst EJ, Hill WH, Krathwohl DR. Taxonomy of educational objectives: handbook Ithe cognitive domain. New York: David McKay, 1956.

38. Shulman L. Making differences: a table of learning. Change 2002;34(6):36-44.

39. Cox M, San Diego JP, Newton T, Hindmarsh J, et al. Measures to assess students' spatial reasoning. Paper presented at Computers and Learning 2009 Conference, March 23-25, 2009, Brighton, UK.

40. San Diego JP, Cox M, Hindmarsh J, Reynolds P, et al. Learning dental-clinical skills with technology-enhanced models. Poster presented at Computers and Learning 2009 Conference, March 23-25, 2009, Brighton, UK.

41. Reynolds PA, Quinn B, Cox MJ. The hapTEL project: a triangulation of educational, curricular, and technical research of haptics in dental education. J Dent Res 2011;90(Spec Iss):103 (Abstract).

42. Roberts C, Carruthers R, Hatzipanagos S, Comfort M, Reynolds PA. An evaluation of an online course for dental surgery assistants in Malaysia. Dent Nurs 2010;6(10): 592-4.

43. Barclay D, Higgins C, Thompson R. The partial least squares (PLS) approach to causal modeling: personal computer adoption and use as an illustration (with commentaries). Technol Stud 1995;2(2):285-324.

44. Fornell C, Bookstein FL. Two structural equation models: LISREL and PLS applied to consumer exit-voice theory. J Marketing Res 1982;19(4):440-52.

45. Chin WW. The partial least squares approach for structural equation modelling. In: Marcoulides GA, ed. Modern methods for business research. Hillsdale, NJ: Lawrence Erlbaum Associates, 1998:295-336. 